\title{
Correction to: Trade agreements and international technology transfer
}

\author{
Inmaculada Martínez-Zarzoso ${ }^{1,3}$ (1) $\cdot$ Santiago Chelala ${ }^{2}$
}

Published online: 30 June 2021

(c) Kiel Institute 2021

\section{Correction to: Review of World Economics https://doi.org/10.1007/s10290-021-00420-7}

In the original publication of the article, the second affiliation of the author Inmaculada Martinez-Zarzoso was missed to be added. It should read as below.

University Jaume I, Castellón, Spain.

The author Santiago Chelala is affiliated only to the University of Buenos Aires, not to the University of Goettingen.

The original article has been corrected.

Publisher's Note Springer Nature remains neutral with regard to jurisdictional claims in published maps and institutional affiliations.

The original article can be found online at https://doi.org/10.1007/s10290-021-00420-7.

Inmaculada Martínez-Zarzoso

imartin@gwdg.de

1 University of Goettingen, Goettingen, Germany

2 University of Buenos Aires, Buenos Aires, Argentina

3 University Jaume I, Castellón, Spain 